\title{
EFFECT OF SCAFFOLD MICROARCHITECTURE ON OSTEOGENIC DIFFERENTIATION OF HUMAN MESENCHYMAL STEM CELLS
}

\author{
Ameya Phadke ${ }^{1, \S}$, YongSung Hwang ${ }^{1, \S}$, Su Hee Kim², Soo Hyun Kim², Tomonori Yamaguchi' ${ }^{3,4}$, Koichi Masuda ${ }^{3}$ \\ and Shyni Varghese ${ }^{1, *}$
}

\author{
${ }^{1}$ Department of Bioengineering, University of California-San Diego, San Diego, CA, USA \\ ${ }^{2}$ Biomaterials Research Centre, Korea Institute of Science and Technology, Seoul, Republic of Korea \\ ${ }^{3}$ Department of Orthopaedic Surgery, University of California-San Diego, San Diego, CA, USA \\ ${ }^{4}$ Graduate School of Life and Medical Sciences, Doshisha University, Kyoto, Japan
}

${ }^{\S}$ Both authors contributed equally to this work

\begin{abstract}
Design of macroporous synthetic grafts that can promote infiltration of cells, their differentiation, and synthesis of bone-specific extracellular matrix is a key determinant for in vivo bone tissue regeneration and repair. In this study, we investigated the effect of the microarchitecture of the scaffold on osteogenic differentiation of human mesenchymal stem cells (hMSCs). Poly(ethylene glycol) diacrylate-co-N-acryloyl 6-aminocaproic acid cryogels were fabricated to have either a pore network consisting of cellular, randomly oriented pores (termed 'spongy') or a pore network consisting of lamellar columns (termed 'columnar'), with both cryogel types showing a similar porosity. Both spongy and columnar cryogels supported comparable levels of cell viability and proliferation of hMSCs in vitro. However, spongy cryogels promoted osteogenic differentiation to a greater extent than their columnar counterparts, as evidenced by increased alkaline phosphatase activity and osteoblastic gene expression over 21 days post culture. Leveraging upon our previous work, we further evaluated the ability of these synthetic scaffolds in conjunction with mineralisation to promote ectopic bone formation upon subcutaneous implantation in nude rats. Mineralised spongy and columnar cryogels, both in the presence and absence of exogenous hMSCs, promoted ectopic bone formation in vivo. No such bone formation was observed in acellular cryogels devoid of mineralisation, with extensive host cell infiltration and vascularisation in columnar cryogels, and negligible infiltration into spongy cryogels. Our results thus present a novel method to tune the microarchitecture of porous polymeric scaffolds, in addition to suggesting their efficacy as synthetic bone grafts.
\end{abstract}

Key words: Mesenchymal stem cells; synthetic grafts; spongy cryogels; columnar cryogels; osteoblastic genes; bone formation.

*Address for correspondence:

Shyni Varghese

Department of Bioengineering, University of CaliforniaSan Diego

9500 Gilman Drive, MC 0412

La Jolla, CA 92093, USA

Telephone number: $+1-858-822-7920$

FAX Number: +1-858-534-5722

Email: svarghese@ucsd.edu

\section{Introduction}

Mesenchymal stem cells (MSCs) are multipotent progenitors that have been isolated from a variety of adult tissues and are capable of self-renewal as well as differentiation into bone, fat, and cartilage under specific culture conditions (Phadke et al., 2010a). Osteogenic differentiation of MSCs is characterised by increased alkaline phosphatase (ALP) activity, expression of bonespecific markers (including the transcription factor Runx2, as well as matrix proteins such as osteocalcin $(\mathrm{OCN})$, bone sialoprotein (BSP), and osteopontin (OP)), and the deposition of calcified matrix (Jaiswal et al., 1997; Hwang et al., 2007; Hwang et al., 2009a). Indeed, the differentiation of MSCs into the osteoblastic lineage has been touted as a promising strategy for in vivo regeneration and repair of damaged bone tissue (Kadiyala et al., 1997; Bruder et al., 1998; Cowan et al., 2004). For the effective therapeutic application of MSCs in bone repair and regeneration, it is necessary to utilise scaffolds that support osteogenic differentiation of progenitor/stem cells and vascularisation of the implant. Emerging studies clearly indicate the role of extracellular cues arising from the matrix on directing osteogenic commitment of stem cells. In particular, the structural, topographical, physical, and chemical characteristics of the matrix play an important role in determining osteogenic differentiation of progenitor cells and bone tissue formation (Curran et al., 2006; Engler et al., 2006; Dalby et al., 2007; Benoit et al., 2008; Yuan et al., 2010; Ayala et al., 2011).

The microarchitecture of the scaffold plays an important role in osteogenic differentiation of stem cells in a 3-dimensional environment, as differences in microstructure can influence cell infiltration, nutrient transport, extracellular matrix accumulation, cellcell communications through soluble factors, and vascularisation (Zeltinger et al., 2001; Karageorgiou and Kaplan, 2005; Hutmacher et al., 2007; Birmingham et al., 2012). Given these effects of scaffold pore microarchitecture, it is important to gain an understanding of its effect on the osteogenesis of human MSCs (hMSCs). The hierarchical structure of native bone tissue suggests that the pore architecture could play a key role in osteogenic differentiation. For instance, trabecular and cortical bone possess significantly different pore architecture. Trabecular bone is highly porous (70-90\% porosity) with isotropic, cellular pore architecture (Galante et al., 1970), while cortical bone is much denser than 
trabecular bone with $>15 \%$ porosity, with a pore network of oriented, columnar pores (known as a Haversian system) (Schaffler and Burr, 1988; Wang and Ni, 2003).

Previous studies have demonstrated the effect of pore structure (pore size, shape, interconnectivity, and porosity) on the in-growth of bone tissue, as well as ectopic bone induction in vivo (Kühne et al., 1994; Tsuruga et al., 1997; Gauthier et al., 1998; Mastrogiacomo et al., 2006; Von Doernberg et al., 2006; Kim et al., 2010). Similarly, studies have also shown the effect of pore architecture of ceramic scaffolds on the activity of murine osteoblasts in vitro $(\mathrm{Fu}$ et al., 2009). However, the effect of pore architecture (i.e., pore shape and morphology of pore network) on in vitro osteogenic differentiation of hMSCs is unclear, though previous studies have elucidated the effect of pore size and porosity on osteogenesis (Gomes et al., 2006; Kasten et al., 2008). To this end, we have investigated the role of the microarchitecture of scaffolds on the osteogenesis of hMSCs using cryogels with distinctly different pore architecture, while having similar porosity. Specifically, we have utilised poly(ethylene glycol)-co-N-acryloyl 6-aminocaproic acid (PEGDA-co-A6ACA) cryogels with two types of pore architecture: spongy pore architecture, consisting of an isotropic network of cellular pores, and columnar pore architecture, having a directional network of plate-like columnar pores. The cryogels with different architectures were fabricated by using a new method involving principles of cryogelation (Hwang et al., 2009b).

\section{Materials and Methods}

\section{Monomer synthesis}

$\mathrm{N}$-acryloyl 6-aminocaproic acid (A6ACA) and poly(ethylene glycol)-diacrylate $\left(\mathrm{M}_{\mathrm{n}}: 3.4 \mathrm{kDa}\right)$ (PEGDA3.4K) were synthesised as previously described (Zhang et al., 2009; Ayala et al., 2011).

\section{Cryogel synthesis}

Cryogels were prepared in cylindrical polypropylene moulds measuring $3 \mathrm{~mm}$ in diameter. For columnar cryogels, $40 \mu \mathrm{L}$ of deionised (DI) $\mathrm{H}_{2} \mathrm{O}$ was added to the moulds and chilled at $-20{ }^{\circ} \mathrm{C}$ prior to cryogelation to create a thin ice layer at the bottom of the mould (referred to as 'columnar moulds'). For cryogels with spongy pore structure, moulds were chilled at $-20{ }^{\circ} \mathrm{C}$ without DI $\mathrm{H}_{2} \mathrm{O}$ (referred to as 'spongy' moulds). Both spongy and columnar moulds were chilled in a covered dry polystyrene Petri dish.

A solution of $9.25 \% \mathrm{w} / \mathrm{v}$ A6ACA, $20 \% \mathrm{w} / \mathrm{v}$ PEGDA3.4K was prepared in $0.5 \mathrm{M}$ sodium hydroxide and chilled to $4{ }^{\circ} \mathrm{C}$ for $1 \mathrm{~h}$. To this chilled precursor solution, $0.15 \%$ tetramethylethylenediamine and $0.5 \%$ ammonium persulphate were added to initiate polymerisation. Immediately, $60 \mu \mathrm{L}$ of the resulting solution was added to spongy and columnar moulds respectively, and placed inside covered dry polystyrene Petri dishes. This setup was then placed at $-20^{\circ} \mathrm{C}$ and allowed to polymerise for $24 \mathrm{~h}$. Following polymerisation, both spongy and columnar cryogels were removed from moulds, thawed at room temperature and immersed in $1 \mathrm{X}$ phosphate-buffered saline (PBS).

\section{Micro-computed tomography}

To characterise the pore structure, the cryogels were soaked in a $10 \%$ solution of $\mathrm{FeCl}_{3}$ in $\mathrm{DI} \mathrm{H}_{2} \mathrm{O}$ for $2 \mathrm{~h}$, frozen at $-80{ }^{\circ} \mathrm{C}$, and then lyophilised. The function of the $\mathrm{FeCl}_{3}$ was to provide $\mathrm{Fe}^{3+}$ ions to bind to the anionic A6ACA moieties, causing iron salt formation on the internal surface of the cryogels upon lyophilisation. The $\mathrm{FeCl}_{3}$ salts on the internal pore layer served to increase contrast during radiographic imaging. The 3-dimensional internal pore structure of the cryogels was non-invasively imaged using the SkyScan 1076 High Resolution In-Vivo Micro-Computed Tomography Scanner (SkyScan, Bruker MicroCT, Kontich, Belgium), at $9 \mu \mathrm{m} /$ pixel resolution. Scans were reconstructed from projections using NRecon software (SkyScan) and converted to 3-dimensional objects using DataViewer software (SkyScan). Additionally, porosity measurements were carried out using CTAn software (SkyScan).

\section{Scanning electron microscopy}

The microstructures of PEGDA-co-A6ACA cryogels were examined using scanning electron microscopy (SEM, Philips XL30 ESEM, Eindhoven, The Netherlands). Briefly, the samples were dehydrated in $50 \%, 75 \%$ and $100 \%$ ethanol and dried using a critical point dryer (Tousimis AutoSamdri 815; Tousimis, Rockville, MD, USA). After samples were completely dried, they were iridium-coated using a sputter coater (Emitech K575X Sputter Coater; Quorum Technologies, East Grinstead, West Sussex, UK) for $8 \mathrm{~s}$ prior to SEM imaging.

\section{Mercury intrusion porosimetry}

A mercury intrusion porosimeter (MIP) (Micromeritics AutoPore IV9500, Oak Ridge, TN, USA) was used to determine the internal pore size distribution, pore surface area, and porosity. Briefly, the samples were serially dehydrated in $50 \%, 75 \%$ and $100 \%$ ethanol. They were then dried using a critical point dryer (Tousimis AutoSamdri 815) in which they were subjected to a pressure cycle starting at approximately 0.5 psia and then increasing to $60000 \mathrm{psia}$. Based on the amount of intrusion of mercury into samples via their internal pore structures, the analysis was performed using AutoPore IV9500 v1.07 software. A total of $0.1 \mathrm{~g}$ of each sample was used for the measurement.

\section{Cell culture}

HMSCs (Center for Regenerative Medicine, Texas A \& M University, College Station, TX, USA) were expanded at $37{ }^{\circ} \mathrm{C}, 5 \% \mathrm{CO}_{2}$ in growth medium consisting of highglucose DMEM (Gibco/Life Technologies, Carlsbad, CA, USA), $8.97 \%$ foetal bovine serum (Hyclone/ ThermoScientific, Rockford, MD, USA), $1.8 \mathrm{mM}$ L-glutamine (Gibco), and passaged at $70 \%$ confluence using $0.25 \%$ trypsin-EDTA (Invitrogen). Cells were utilised at passage 6 for seeding within the cryogel-based scaffolds. 
Table 1. List of primers used for real-time PCR.

\begin{tabular}{|c|c|c|c|c|}
\hline Gene & $\begin{array}{c}\text { Gene } \\
\text { (Abbreviation) }\end{array}$ & Direction & Primer Sequence & $\begin{array}{c}\text { Amplicon size } \\
\text { (bp) }\end{array}$ \\
\hline \multirow{2}{*}{$\begin{array}{l}\text { Glyceraldehyde } \\
\text { 3-phosphate } \\
\text { dehydrogenase }\end{array}$} & \multirow{2}{*}{ GAPDH } & Forward & 5' CAT CAA GAA GGT GGT GAA GC 3' & \multirow{2}{*}{177} \\
\hline & & Reverse & 5' GTT GTC ATA CCA GGA AAT GAG C 3' & \\
\hline \multirow{2}{*}{ Osteocalcin } & \multirow{2}{*}{$\mathrm{OCN}$} & Forward & 5' GAA GCC CAG CGG TGC A 3' & \multirow{2}{*}{70} \\
\hline & & Reverse & 5' CAC TAC CTC GCT GCC CTC C 3' & \\
\hline \multirow{2}{*}{$\begin{array}{c}\text { Runt-related } \\
\text { Transcription Factor } 2\end{array}$} & \multirow{2}{*}{ RUNX2 } & Forward & 5' CCA CCC GGC CGA ACT GGT CC 3' & \multirow{2}{*}{258} \\
\hline & & Reverse & $5^{\prime}$ CCT CGT CCG CTC CGG CCC ACA 3' & \\
\hline \multirow{2}{*}{ Osteopontin } & \multirow{2}{*}{ OPN } & Forward & 5' CCA AGT AAG TCC AAC GAA AG 3' & \multirow{2}{*}{348} \\
\hline & & Reverse & 5' GGT GAT GTC CTC GTC TGT A 3' & \\
\hline
\end{tabular}

\section{Cryogel sterilisation}

Following synthesis, cryogels were immersed in 1X PBS for $24 \mathrm{~h}$ (with twice a change of solution) to remove the unreacted materials. Cryogels were then sterilised by immersion in $70 \%$ ethanol for $12 \mathrm{~h}$ and washed in $1 \mathrm{X}$ sterile PBS for at least 3 days (with at least twice daily changes of solution) to remove residual ethanol. Cryogels were immersed in growth medium at $37{ }^{\circ} \mathrm{C}, 5 \% \mathrm{CO}_{2}$ for $18 \mathrm{~h}$ prior to cell seeding.

\section{Cell seeding}

At the time of seeding, cryogels were dried under sterile conditions for $105 \mathrm{~min}$, resulting in an approximately $50 \%$ and $40 \%$ loss of weight through evaporation for spongy and columnar cryogels, respectively. Cryogels were then seeded with cells at a density of $8 \times 10^{5}$ cells/ construct. Briefly, hMSCs were suspended in growth medium at $1.33 \times 10^{7}$ cells $/ \mathrm{mL}$. $60 \mu \mathrm{L}$ of this suspension was then seeded on top of each construct at various spots. The seeded constructs were then incubated in the absence of additional medium at $37^{\circ} \mathrm{C}, 5 \% \mathrm{CO}_{2}$ for $3 \mathrm{~h}$ to allow for cell attachment. Following this, cell-laden cryogels were incubated in excess growth medium for $24 \mathrm{~h}$ at $37{ }^{\circ} \mathrm{C}, 5 \% \mathrm{CO}_{2}$. Subsequently, cryogels were cultured for up to 21 days in osteogenic medium consisting of high-glucose DMEM (Gibco), 10 \% FBS (Hyclone), $10 \mathrm{mM} \beta$-glycerophosphate (Calbiochem/MerckMillipore, Darmstadt, Germany), 100 nM dexamethasone (SigmaAldrich, St. Louis, MO, USA) $10 \mu \mathrm{g} / \mathrm{mL}$ ascorbic acid-2phosphate (Sigma-Aldrich), and 50 units $/ \mathrm{mL}$ penicillinstreptomycin (Gibco). Medium was changed every $48 \mathrm{~h}$ and samples were collected for analysis at different time points as detailed below.

\section{Cell viability}

Following $24 \mathrm{~h}$ after culture in growth medium post-seeding, cryogels were analysed for viability of the seeded cells. The cryogels were cut into slices, stained with a Live/Dead Viability/Cytotoxicity Kit (Invitrogen/Life Technologies) and subsequently visualised using fluorescent microscopy to distinguish live cells (stained green by calcein-AM) from dead cells (stained red by ethidium homodimer). Viability was estimated by comparing the number of live cells to the total number of cells.

\section{Quantitative PCR}

Cell-laden cryogels (constructs) were analysed for expression of osteogenic markers as a function of culture time at 4, 7, 14 and 21 days, and compared to day 0 hMSCs collected at the time of seeding. Constructs $(n=3$ per group, per time point) were homogenised in TRIzol (Invitrogen); RNA was extracted from this homogenate according to the manufacturer's instructions. $600 \mathrm{ng}$ of RNA was reverse-transcribed to cDNA using iScript cDNA synthesis kit (Bio-Rad) according to the manufacturer's instructions. The resultant cDNA was then analysed for expression of osteogenic markers - Runx2, osteocalcin (OCN), and osteopontin (OPN) with glyceraldehyde 3-phosphate dehydrogenase (GAPDH) as a housekeeping gene. Expression at each time point was normalised to day 0 and expressed as fold change thereof. Real-time PCR reactions were run on a Model 7300 Real-time PCR Cycler (Applied Biosystems/Life Technology), using Power SYBR I Mastermix (Applied Biosystems). Expression level of various genes was calculated as previously described (Varghese et al., 2010). The RT-PCR primers used are listed in Table 1.

\section{Alkaline phosphatase activity}

Cell-laden spongy and columnar cryogels were assayed for activity of alkaline phosphatase (ALP) using enzymatic dephosphorylation of para-nitrophenolphosphate ( $\mathrm{p}-\mathrm{NPP}$ ) to para-nitrophenol (n-NP) at various time points $(4,7$, 14 and 21 days) using an ALP Substrate Kit (Bio-Rad, Hercules, CA, USA). Briefly, constructs ( $n=3$ per group per time point) were homogenised in $500 \mu \mathrm{L}$ of $0.75 \mathrm{M}$ of 2-amino-2-methyl-1-propanol $(\mathrm{pH} \mathrm{10.3)}$ on ice and stored at $-20{ }^{\circ} \mathrm{C}$. Assay substrate solution was prepared according to the manufacturer's instructions. $120 \mu \mathrm{L}$ of sample solution was combined with $480 \mu \mathrm{L}$ of assay substrate solution and incubated at room temperature for $2 \mathrm{~min}$; the absorbance of this solution was measured at $405 \mathrm{~nm}$ every $30 \mathrm{~s}$ for $7 \mathrm{~min}$ using a DU730 UV/Vis spectrophotometer (Beckman Coulter, Brea, CA, USA). A graph of absorbance $v s$. time was plotted and the slope was determined by means of a linear fit to calculate the rate of reaction. A higher slope indicates increased ALP activity. ALP activity was expressed as change in absorbance per minute per construct wet weight. 


\section{Calcium content}

Constructs were assayed for calcium content at 7 and 21 days. At each time point, cell-seeded as well as acellular cryogels ( $n=3$ per group) were collected and lyophilised. After measuring their dry weight, lyophilised constructs were homogenised in $0.5 \mathrm{ml}$ of $0.5 \mathrm{M} \mathrm{HCl}$. The homogenates were vigorously vortexed for $16 \mathrm{~h}$ at $4^{\circ} \mathrm{C}$. The calcium concentration was measured spectrophotometrically at $570 \mathrm{~nm}$ with o-cresolphthalein complexone using a two reagent calcium kit (Pointe Scientific, Canton, MI, USA) according to the manufacturer's instructions. The total calcium content of each construct was normalised to its dry weight. Moreover, poly(ethylene glycol) hydrogelscontaining A6ACA moieties have been previously shown to undergo mineralisation in serum-supplemented solutions containing $\mathrm{Ca}^{2+}$ and $\mathrm{PO}_{4}^{3-}$ (Phadke et al., 2010b). To correct for this, the calcium content of the corresponding acellular construct was subtracted from the average cellular calcium content of the cell-seeded constructs.

\section{DNA content}

Cell-seeded cryogels $(n=3)$ were collected at 0,7 and 21 days for analysis of DNA content. Samples were frozen at $-80{ }^{\circ} \mathrm{C}$, lyophilised and digested in papain solution $(0.125 \mathrm{mg} / \mathrm{mL}$ papain [Worthington Biochemicals, Lakewood, NJ, USA], $10 \mathrm{mM}$ phosphate and $10 \mathrm{mM}$ EDTA, $\mathrm{pH}=6.3$ ) for $16 \mathrm{~h}$ at $60{ }^{\circ} \mathrm{C}$. DNA was then measured in the papain digests using the Quant-IT Picogreen dsDNA kit (Invitrogen).

\section{Histology for in vitro samples}

Constructs cultured in vitro were collected at 21 days for histology. Samples were fixed for $24 \mathrm{~h}$ in $4 \%$ paraformaldehyde (PFA) and stored in $70 \%$ ethanol at $4{ }^{\circ} \mathrm{C}$. The fixed constructs were dehydrated in graded concentrations of ethanol followed by subsequent immersion in Histo-Clear (National Diagnostics; www. nationaldiagnostics.com), embedded in paraffin and cut into $10 \mu \mathrm{m}$ thick sections. Sections were then analysed through immunofluorescent staining for osteocalcin. Briefly, the sections were deparaffinised in xylene and gradually rehydrated through a series of decreasing ethanol concentrations. The re-hydrated sections were blocked with blocking buffer consisting of $3 \%$ bovine serum albumin (Sigma-Aldrich), $0.1 \%$ Triton-X 100 (Sigma-Aldrich) in PBS for $30 \mathrm{~min}$ and then exposed to primary antibody (osteocalcin anti-mouse, monoclonal; Abcam, Cambridge, UK; ab13420) diluted 1:100 in blocking buffer for $1 \mathrm{~h}$. After washing sections with PBS (30 min), samples were exposed to secondary antibody (Alexa Fluor 568 goat antimouse, Molecular Probes/Life Technologies) diluted 1:250 in blocking buffer for $60 \mathrm{~min}$. Following this, sections were washed with PBS for $30 \mathrm{~min}$, mounted on glass slides with Vecta Shield/DAPI (Vector Laboratories, Burlingame, CA, USA) and visualised using fluorescent microscopy.

\section{Mineralisation of cryogels}

Mineralised samples were prepared by a procedure described previously with some modifications (Phadke et al., 2010b). Cryogels were immersed in $\mathrm{DI} \mathrm{H}_{2} \mathrm{O}$ for $24 \mathrm{~h}$, dried at $37^{\circ} \mathrm{C}$ and swollen in simulated body fluid (SBF) as detailed previously (Oyane et al., 2003). The SBF-swollen cryogels were then partially dried for $60 \mathrm{~min}$ at room temperature on tissue paper to remove excess SBF from the pores and immersed in a solution of $40 \mathrm{mM} \mathrm{Ca}^{2+} / 24 \mathrm{mM}$ $\mathrm{HPO}_{4}^{2-}$ at $\mathrm{pH} 5.2$ for $1 \mathrm{~h}$ on an orbital shaker at $300 \mathrm{rpm}$ at $25^{\circ} \mathrm{C}$. Following immersion, cryogels were rinsed briefly in running DI $\mathrm{H}_{2} \mathrm{O}$ and incubated in SBF for $48 \mathrm{~h}$, with daily change of solution. The samples were then soaked in PBS for $6 \mathrm{~h}$, sterilised by immersion in $70 \%$ ethanol for $6 \mathrm{~h}$ and incubated in sterile PBS for 3 days with at least 2 times daily solution change to remove residual ethanol.

\section{Cell seeding of mineralised cryogels}

For cellular mineralised constructs, mineralised cryogels were incubated in hMSC growth medium for $18 \mathrm{~h}$, dried under sterile conditions for $105 \mathrm{~min}$ and seeded with hMSCs at passage 6 , as detailed above. Cell-seeded cryogels were incubated in growth medium at $37{ }^{\circ} \mathrm{C}$, $5 \% \mathrm{CO}_{2}$ for 1 week to allow for their attachment and proliferation prior to subcutaneous implantation.

\section{Subcutaneous implantation}

Five athymic male rats, 12-months-old, weighing 400 to $450 \mathrm{~g}$ were used in the present study with the approval of the Institutional Animal Care and Use Committee. After intraperitoneal administration of ketamine hydrochloride $\left(75 \mathrm{mg} / \mathrm{kg}\right.$, Ketaset $^{\circledR}$, Fort Dodge, IA, USA) and xylazine (3 mg/kg, AnaSed ${ }^{\circledR}$, Akorn, Lake Forest, IL, USA), the rats were placed into a prone position and prepared in a standard surgical fashion. A single midline incision $(1.5 \mathrm{~mm})$ on the back of the rat was made, and four subcutaneous pouches (cranial-left and -right and caudalleft and -right) were constructed by blunt dissection using a $1 \mathrm{~cm}$ wide spatula. A cryogel (either mineralised-acellular, non-mineralised-acellular or mineralised-hMSC-seeded) was inserted into the end of each pouch. For acellular cryogels, one sample of each group (spongy mineralised, spongy non-mineralised, columnar mineralised, columnar non-mineralised) was implanted in each rat, with three rats receiving these acellular cryogels (four cryogels - one per acellular group - per rat). For the hMSC-seeded cryogels, two samples of each group were implanted in each of the remaining two rats (four cryogels - two per hMSC-seeded group - per rat). The specific subcutaneous pouch (cranialleft and -right, caudal-left and -right) for each group was rotated in different rats to ensure that implantation site did not provide a bias. Following implantation, the skin was closed using staples.

\section{Radiograph and sampling of implanted samples}

Anterior-posterior (AP) digital radiographs (NAOMI; $356 \mathrm{dpi}, 71 \mu \mathrm{m}$ pixel size, Tokyo, Japan) of the rats were obtained $(55 \mathrm{kV}, 10 \mu \mathrm{A})$ pre- and post-operatively. Hard tissue formation was evaluated for all experimental samples radiographically at each time point $(0,2,4,6$ and 9 weeks post implantation). All animals were sacrificed with $\mathrm{CO}_{2}$ and cervical dislocation at 9 weeks after surgery. Subcutaneously implanted samples were excised following animal sacrifice and photographed to assess host cell infiltration. Samples were then fixed in $4 \%$ PFA in PBS for $96 \mathrm{~h}$ and stored in $70 \%$ ethanol at $4{ }^{\circ} \mathrm{C}$. 


\section{Micro-computed tomography of subcutaneously implanted samples}

Excised implants at 9 weeks (one representative sample per each experimental group) were visualised through micro-computed tomography (micro-CT) simultaneously during fixation in PFA with the SkyScan 1076 High Resolution In-Vivo Micro-Computed Tomography Scanner (SkyScan, Belgium), at $9 \mu \mathrm{m} /$ pixel resolution. Scans were reconstructed from projections using NRecon software (SkyScan) and converted to 3-dimensional models using CTAn software (SkyScan).

\section{Histology of subcutaneously implanted samples}

The excised implants were embedded in paraffin, cut into $4 \mu \mathrm{m}$-thick sections and stained either using haematoxylineosin (H \& E) or through immunohistochemistry. Paraffin embedding, sectioning and $\mathrm{H} \& \mathrm{E}$ staining were carried out by San Diego Pathologists Medical Group (San Diego, CA, USA). For immunohistochemical staining, unstained sections were deparaffinised in CitriSolv (Fisherbrand/ Fisher Scientific) and gradually rehydrated through series of decreasing ethanol concentrations and then treated for 5 min with $0.05 \%$ SDS, $12.5 \mathrm{mM}$ Tris, $96 \mathrm{mM}$ glycine. Sections were then blocked with blocking buffer for $60 \mathrm{~min}$ at room temperature, following which they were exposed to primary antibody (osteocalcin anti-mouse) diluted 1:100 in blocking buffer for $18 \mathrm{~h}$ at $4{ }^{\circ} \mathrm{C}$. Sections were then washed in PBS for $30 \mathrm{~min}$ and exposed to $0.3 \%$ hydrogen peroxide in PBS for $20 \mathrm{~min}$ at room temperature to block endogenous peroxidase activity. Samples were exposed to HRP-conjugated secondary antibody (goat anti-mouse IgG-HRP, Santa Cruz Biotechnology, Santa Cruz, CA, USA; sc-2031) diluted 1:100 in blocking buffer for $60 \mathrm{~min}$ at room temperature, washed with PBS for $30 \mathrm{~min}$ and developed using a diaminobenzidine (DAB) substrate kit (Vector Labs) according to the manufacturer's instructions. Samples were then briefly washed with PBS to remove excess DAB and visualised using bright-field microscopy.

\section{In vitro appositional mineralisation of cryogels}

To gain insight into the appearance of the mineralised cryogels due to non-osteogenic appositional mineralisation, mineralised spongy cryogels were allowed to undergo mineralisation in vitro under simulated physiological conditions. Mineralised spongy cryogels were synthesised as specified above, and then immersed in SBF (Oyane et al., 2003) for 7 days at $37^{\circ} \mathrm{C}$ to simulate their appositional mineralisation in vivo. The cryogels were then dehydrated through immersion in graded concentrations of ethanol followed by CitriSolv, embedded in paraffin and cut into
$4 \mu \mathrm{m}$-thick sections. These sections were then stained by $\mathrm{H} \& \mathrm{E}$ and visualised using bright-field microscopy.

\section{Statistical analysis}

The reproducibility of the in vitro effect of scaffold architecture on osteogenesis was confirmed through repeating the experiments independently at least twice, beyond the replicates listed. Statistical significance was determined through two way analysis of variance (ANOVA), with Bonferroni post-test to compare individual groups $(p<0.05)$. Statistical analysis was carried out using Prism 4.6 (Graphpad, La Jolla, CA, USA).

\section{Results}

\section{Development and characterisation of cryogels with varying pore architecture}

Previously, we have shown that the internal microstructure of cryogels can be controlled through various cryogelation parameters such as gelation temperature, degree of supercooling, and kinetics of polymerisation (Hwang et al., 2009b). In the present study, we have harnessed the ability to control the structure of the ice network to develop cryogels with unique internal pore architectures without altering their chemistry or overall porosity (Fig. 1). Indeed, controlling the ice network structure yielded cryogels with two types of distinct pore microstructures, referred to as 'spongy' and 'columnar', (Figs. 1,2). As shown in Fig. 2a,b, a directional cooling front during cryogelation promoted the growth of ice columns perpendicular to the ice-polymer solution interface, and therefore cryogels having a lamellar columnar structure with a larger pore size of approximately $50-60 \mu \mathrm{m}$ in the dried state (corresponding to $\sim 100-150 \mu \mathrm{m}$ in the swollen state, as estimated through bright field microscopy) were synthesised. The pore structure consisted of several oriented lamellae of columns, connected through smaller pores (subsequently referred to as 'columnar pore structure'). On the other hand, their counterparts synthesised without preferential nucleation sites (in spongy moulds) led to a macroporous network consisting of more randomly oriented, interconnected cellular pores measuring approximately $20-30 \mu \mathrm{m}$ in diameter in the dried state (corresponding to $50-60 \mu \mathrm{m}$ in the swollen state, as estimated using bright field microscopy) throughout the constructs as shown in Fig. 2c,d; the interconnected pore network lacked any particular orientation and will subsequently be referred to as 'spongy' pore structure. Between the two structures, the spongy cryogels showed a substantially higher pore area $\left(0.37 \pm 0.18 \mathrm{~m}^{2} / \mathrm{g}\right)$ than

Table 2. Measurements of various microstructural parameters as determined through mercury intrusion porosimetry.

\begin{tabular}{|c|c|c|c|}
\hline Properties & Unit & Spongy & Columnar \\
\hline Total Pore Area & $\mathrm{m}^{2} / \mathrm{g}$ & $0.37 \pm 0.18$ & $0.17 \pm 0.05$ \\
\hline Median Pore Diameter (Volume) & $\mu \mathrm{m}$ & $28.27 \pm 11.99$ & $60.07 \pm 16.36$ \\
\hline Median Pore Diameter (Area) & $\mu \mathrm{m}$ & $19.27 \pm 6.88$ & $30.37 \pm 7.75$ \\
\hline Average Pore Diameter (4V/A) & $\mu \mathrm{m}$ & $26.69 \pm 10.59$ & $45.56 \pm 9.93$ \\
\hline Porosity & $\%$ & $70.0 \pm 0.4$ & $70 \pm 5$ \\
\hline
\end{tabular}


a

$$
\begin{array}{ccc}
\begin{array}{c}
\text { Precursor } \\
\text { solution }
\end{array} & \begin{array}{c}
\text { Ice network } \\
\text { nucleation }
\end{array} & \begin{array}{c}
\text { Ice network } \\
\text { growth }
\end{array}
\end{array}
$$

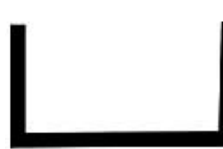

b

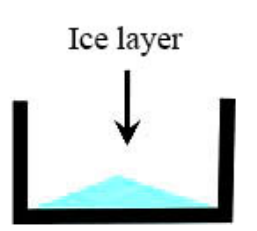

Precursor solution

Fig. 1. Schematic diagram detailing the synthesis of (a) Spongy and (b) Columnar cryogels.

a

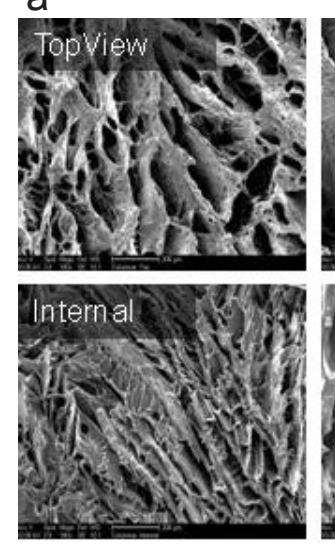

C
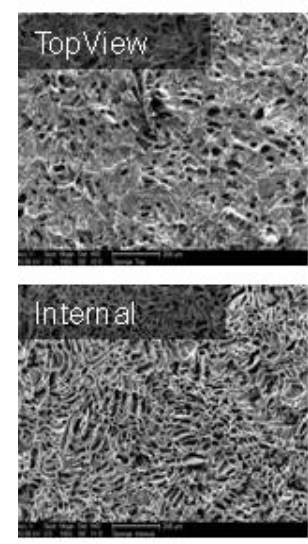
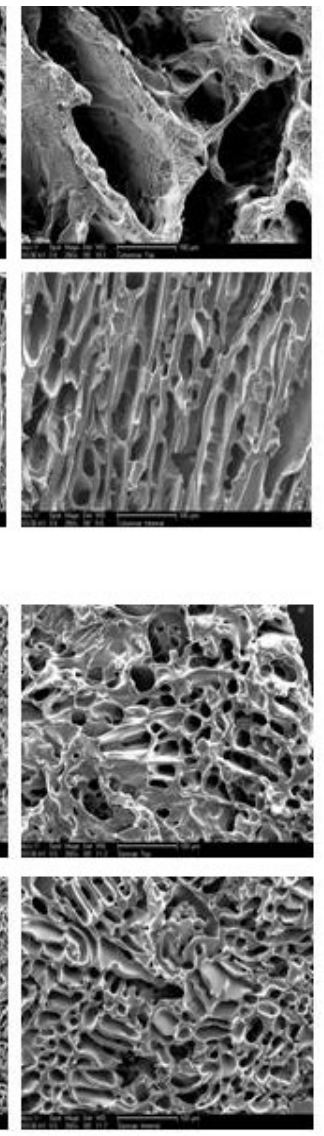

b

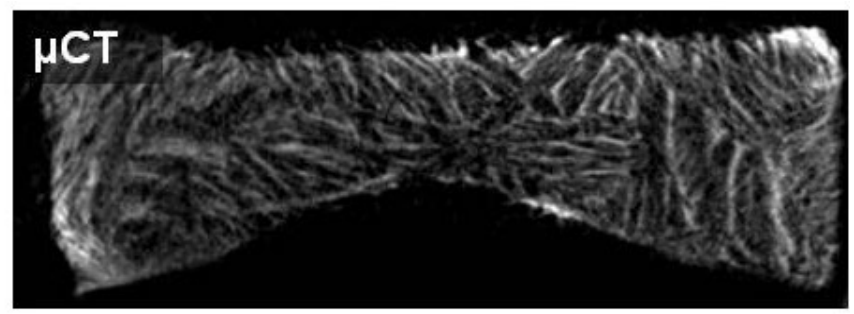

d

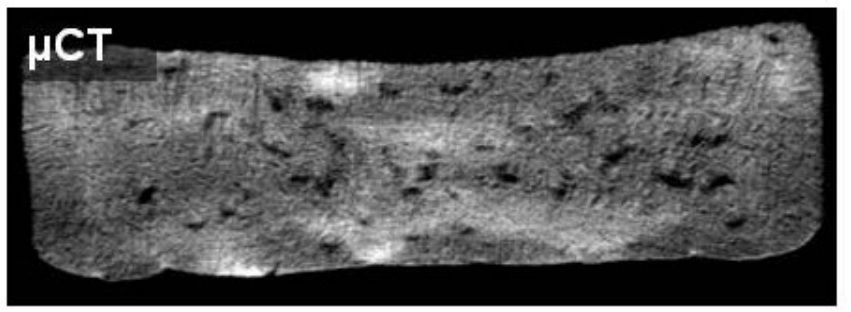

Fig. 2. (a,b) Columnar cryogels visualised through (a) scanning electron microscopy and (b) micro-computed tomography. (c,d) Spongy cryogels visualised through (c) scanning electron microscopy and (d) micro-computed tomography.

the columnar cryogels $\left(0.17 \pm 0.05 \mathrm{~m}^{2} / \mathrm{g}\right)$ (Table 2$)$. Interestingly, despite the vast difference in pore shape and size, mercury intrusion porosimetry suggested similar porosity between the spongy and columnar cryogels; spongy cryogels had a porosity of $70.0 \pm 0.4 \%$ while columnar cryogels had a porosity of $70 \pm 5 \%$. (Table 2 ). Porosity measurements for columnar cryogels were further supported through analysis of the micro-CT reconstructions that suggested a porosity of $67 \%$ for columnar constructs; the small size of pores in the lyophilised spongy cryogels coupled with insufficient resolution of the scanner did not allow for their accurate porosity quantification through micro-CT.
Effect of pore structure on osteogenic differentiation of hMSCs in vitro

Following $24 \mathrm{~h}$ of culture in growth medium, cells showed similar viability $(>90 \%)$ in both spongy and columnar cryogels (Fig 3a,b). A notable difference between the two cryogels, however, was the difference in morphology of the cells within the cryogels. Cells cultured in spongy cryogels showed a more spread morphology (Fig. 3a inset), compared to cells seeded in columnar cryogels, which formed small cellular aggregates along the pore walls (Fig. $3 b)$. DNA quantification at 0,7 and 21 days demonstrated proliferation of cells between 0 and 7 days (approximately 1.5-fold), with both cryogels showing similar DNA content 
a

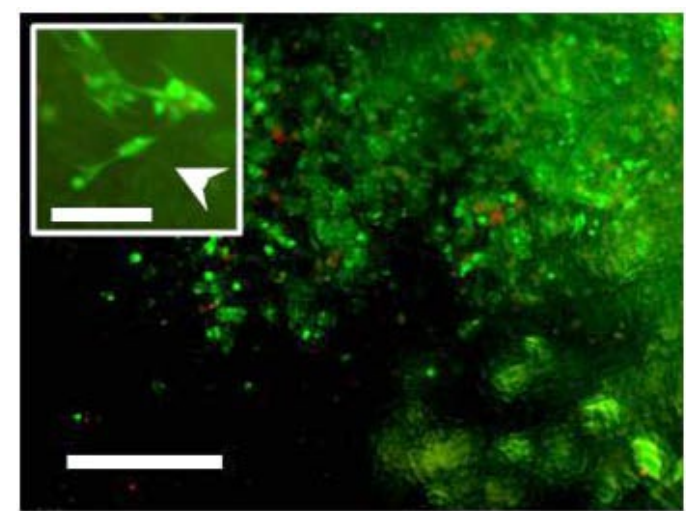

Fig. 3. Live-Dead staining of human mesenchymal stem cells (hMSCs) seeded in the various cryogels after $24 \mathrm{~h}$ in growth medium, prior to their culture in osteogenic medium. (a) Spongy cryogels; the inset image depicts spread cells in a spongy cryogel, indicated by the white arrowhead (inset scale bar: $80 \mu \mathrm{m}$ ). (b) Columnar cryogels; white arrows indicate the cellular aggregates formed in columnar cryogel; scale bars in main images represent $400 \mu \mathrm{m}$; live cells are stained green, dead cells are stained red. (c) Proliferation of hMSCs in the spongy and columnar cryogels, calculated through DNA content and normalised to d0. Error bars represent standard error of the mean $(n=3)$. b

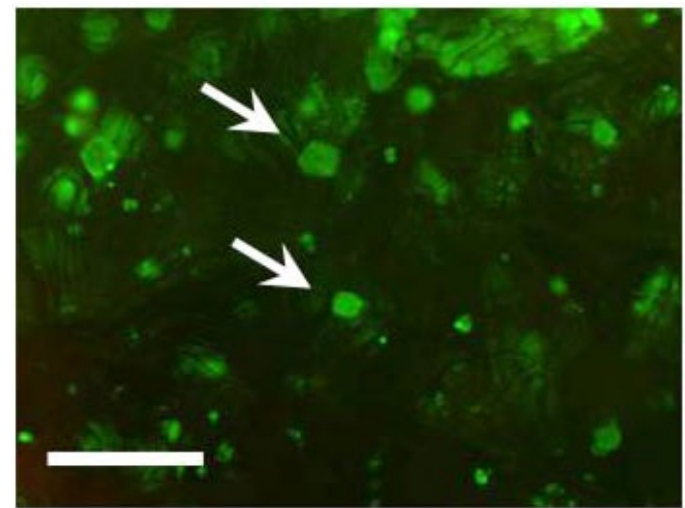

C

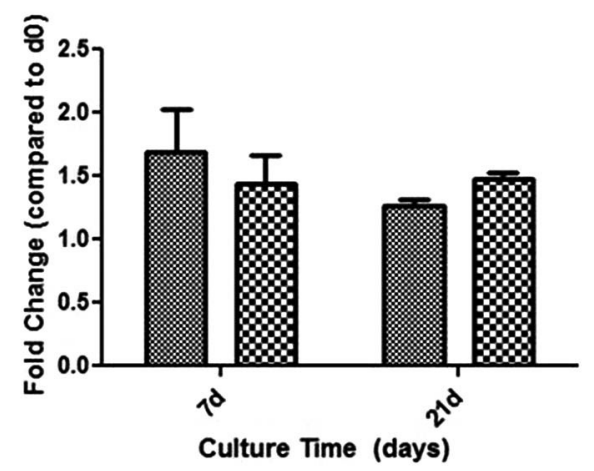

Spongy

Columnar a

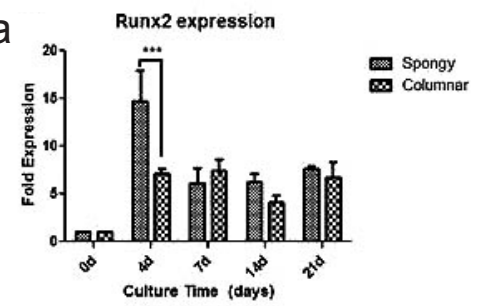

b
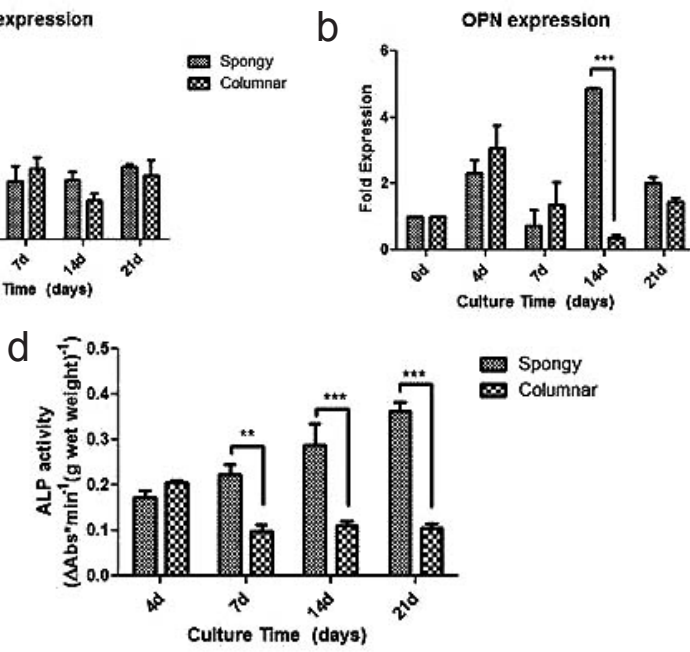

Spongy

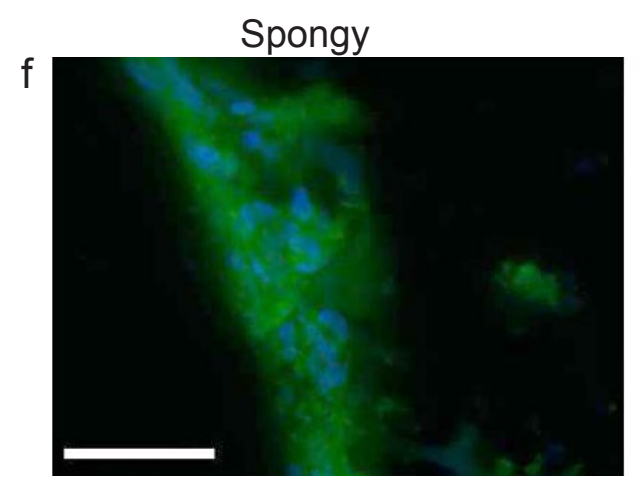

Columnar e

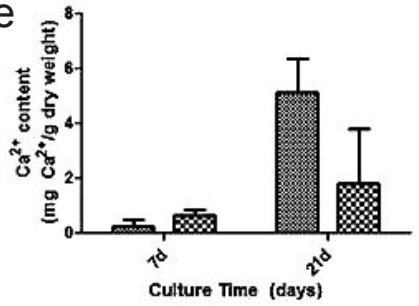

Columnar

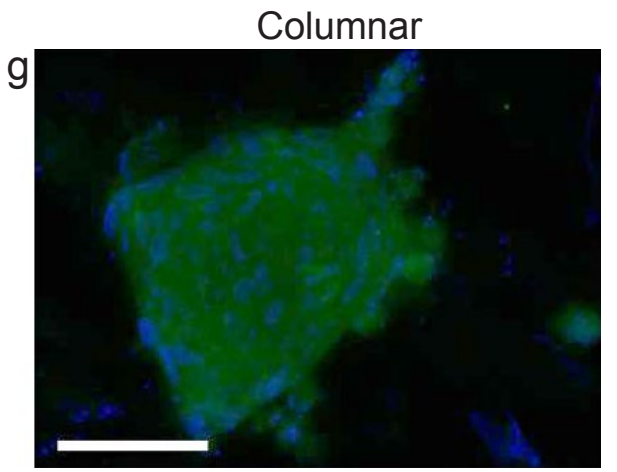

Fig. 4. Expression of osteogenic markers (a) Runx2, (b) osteopontin (OPN), and (c) osteocalcin (OCN) in the spongy and columnar cryogels, (d) alkaline phosphatase activity of hMSCs seeded on spongy and columnar cryogels, (e) calcium content of hMSC-seeded spongy and columnar cryogels at 7 days and 21 days of culture. Error bars represent standard error of the mean $(n=3 ; * *: p<0.01, * * *: p<0.001)$. (f, g) Immunofluorescent staining for OCN at 21 days in (f) Spongy and (g) Columnar cryogels. Green: OCN, Blue: Nuclei. Error bars represent $50 \mu \mathrm{m}$. 
a

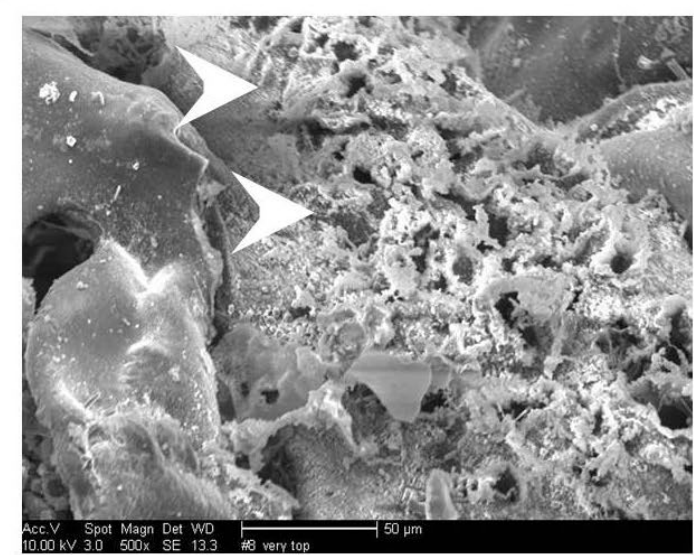

b

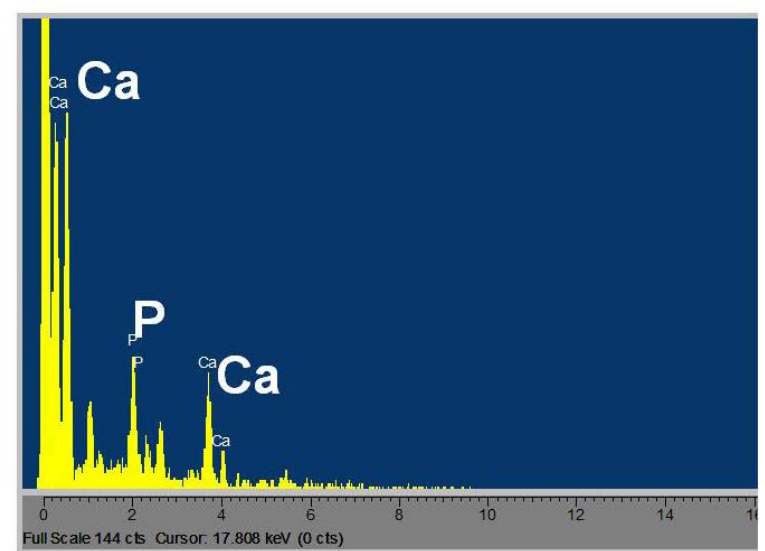

Fig. 5. (a) Scanning electron microscopy image of mineralised A6ACA cryogel prior to implantation with (b) Elemental Dispersive Spectroscopy (EDS) spectrum, indicating presence of calcium and phosphate in the mineralised phase.

(Fig. 3c). However, no significant proliferation was observed between 7 and 21 days. Spongy cryogels showed a slight decrease in cell content with culture time, although the decrease was not statistically significant. The similar DNA content at 7 and 21 days suggests comparable cell proliferation between the spongy and columnar cryogels.

Gene expression analyses suggested that both cryogels supported osteogenic differentiation of the hMSCs compared to day 0 controls, as evidenced by the upregulation of the osteogenic markers Runx $2, \mathrm{OCN}$, and OPN throughout the culture period (Fig. 4a-c). However, there were significant differences in the temporal expression levels depending upon the type of cryogel microstructure. Specifically, cells in spongy cryogels showed significantly higher upregulation of Runx 2 at 4 days of culture, OPN at 14 days of culture and OCN at 21 days of culture, when compared to columnar cryogels. This suggests that the spongy cryogels promoted osteogenic differentiation at a more rapid pace than the columnar cryogels.

The extent of osteogenesis in the cryogels was additionally measured by quantifying the activity of alkaline phosphatase, as well as the cell-mediated calcification. Indeed, spongy cryogels showed substantially higher ALP activity than columnar cryogels at all time points up to 21 days of culture (Fig. 4d). Additionally, we observed that spongy cryogels showed higher calcium content (Fig. 4e), although the difference was not statistically significant. Given the similar DNA content of spongy and columnar cryogels throughout the study, this suggests that the spongy cryogels were more conducive to osteogenic differentiation than the columnar cryogels. Immunofluorescent staining also revealed the presence of OCN in hMSCs cultured in both spongy and columnar cryogels, providing further evidence that these cryogels supported osteogenic differentiation (Fig. 4f,g).

\section{In vivo tissue formation}

Previously, we have demonstrated the ability of mineralised PEG-A6ACA hydrogels to induce osteogenic differentiation of hMSCs, even in the absence of osteogenic-inducing soluble factors and growth factors employing a 2-dimensional culture condition (Phadke et al., 2012). Thus, we next studied the in vivo subcutaneous response to mineralised and non-mineralised cryogels in a nude rat model. The mineralisation of the cryogels was confirmed prior to implantation through scanning electron microscopy and elemental analysis (Fig. 5). Elemental analysis revealed a $\mathrm{Ca} / \mathrm{P}$ ratio of 1.7 , suggesting the presence of an apatite-like mineralised phase. The ability of the implanted cryogels to promote bone tissue formation was evaluated by using a number of different acellular and cellular cryogels. These include (i) acellular columnar cryogels (non-mineralised), (ii) acellular spongy cryogels (non-mineralised), (iii) acellular columnar cryogels (mineralised), (iv) acellular spongy cryogels (mineralised), (v) hMSC-seeded columnar cryogels (mineralised) and (vi) hMSC-seeded spongy cryogels (mineralised). While the acellular scaffold would provide insights into the effect of mineralisation on the osteoinductivity of the scaffolds, the cell-laden mineralised cryogels would provide the effect of exogenous cells on the in vivo bone tissue formation.

Radiographic analyses (by live-animal X-ray imaging) immediately after implantation indicated that the grafts themselves were not radio-opaque and thus were not visible on X-rays (data not shown). Similar to day 0, no evidence of hard tissue formation was observed in radiographs at 2 weeks; however, beginning at 4 weeks, hard tissue was visible in radiographs of all mineralised implants (groups iii-vi) and intensified at 6 and 9 weeks (Fig. 6a,b), irrespective of pore structure or seeding with hMSCs prior to implantation. Mineralised cryogels showed the formation of peripheral hard tissue, as observed through micro-CT analyses of the excised implants at 9 weeks (Fig. $6 \mathrm{c})$.

To investigate the possibility of the appositional mineralisation of the scaffold leading to the appearance of bone-resembling artefacts in histology, we conducted $\mathrm{H} \& \mathrm{E}$ staining of an acellular mineralised spongy cryogel allowed to undergo appositional mineralisation under simulated physiological conditions. Sections of this cryogel 
a

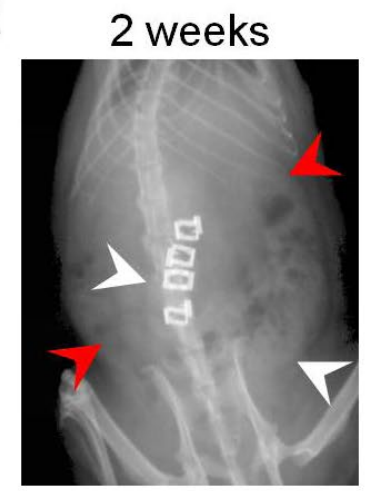

b

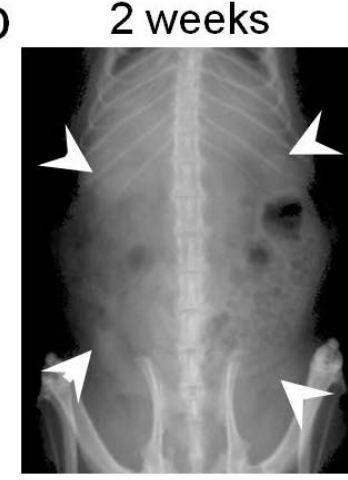

4 weeks

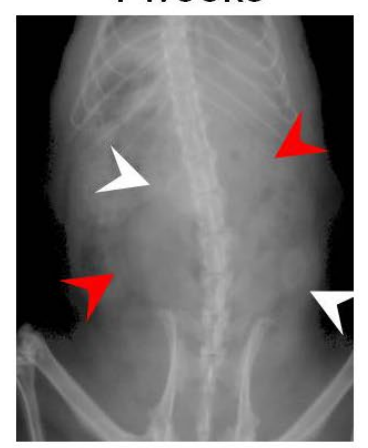

4 weeks

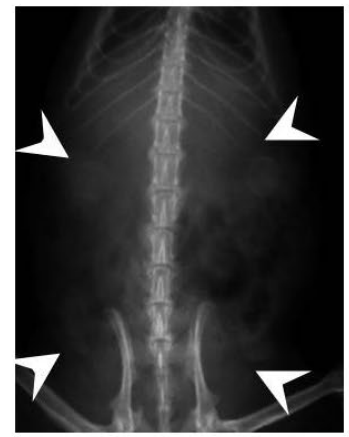

6 weeks

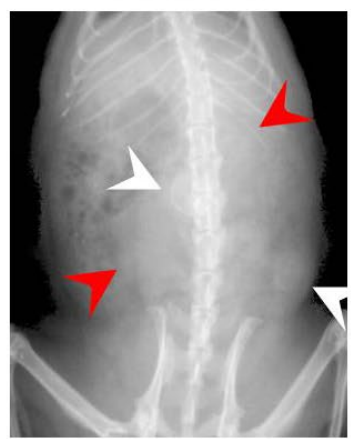

6 weeks

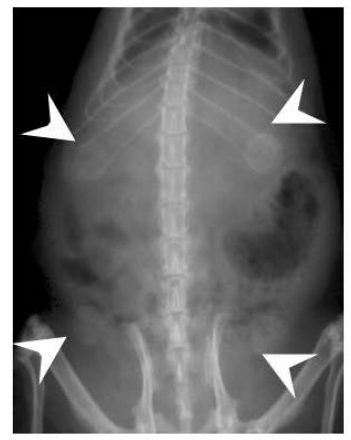

9 weeks

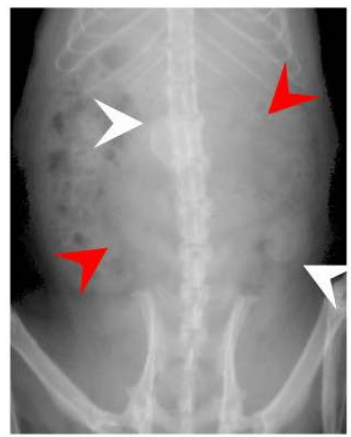

9 weeks

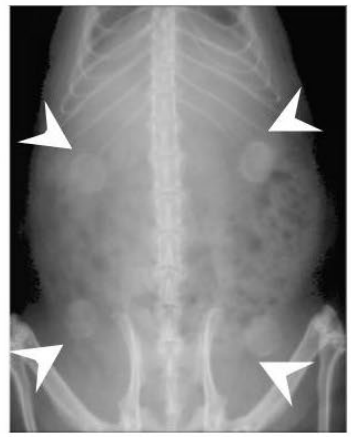

Fig. 6. Ectopic bone formation in subcutaneous implants, evaluated radiographically. (a, b) Digital X-rays for (a) acellular and (b) hMSCseeded cryogels at various time points in representative animals. White arrowheads indicate the location of the mineralised implants, red arrowheads indicate location of the non-mineralised implants. (c) $3 \mathrm{D}$ micro-CT models of the mineralised cryogels after 9 weeks of subcutaneous implantation. Nonmineralised hydrogels could not be imaged due to the lack of hard tissue formation.
C Spongy
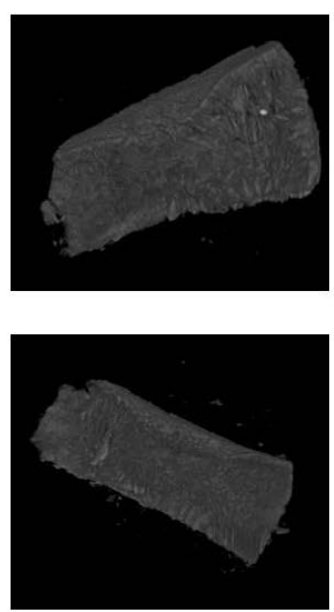

Columnar

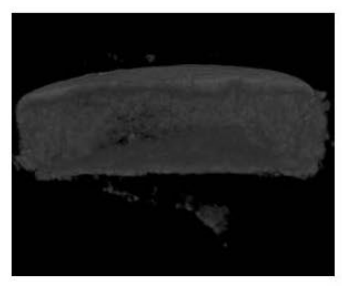

Mineralised, no hMSCs

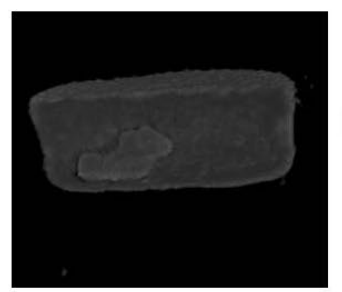

Mineralised, with hMSCs showed the presence of a slightly eosinophilic mineral layer in association with the haematoxylin-stained cryogel surface with the two structures remaining associated after shrinkage during staining (Fig. 7a).

Gross examination of excised implants revealed infiltration of host cells and vascularisation into the mineralised cryogels, irrespective of their pore structure (Fig. 7b-e, inset). In contrast with the acellular mineralised cryogel allowed to undergo appositional mineralisation in vitro, histological analysis of the mineralised cryogels implanted subcutaneously revealed the formation of bonelike tissue in the hard tissue layer, which shrunk away from the scaffold during staining accompanied by the in-growth of host vasculature into the mineralised scaffolds. This suggested that the mineralisation of the cryogels played a crucial role in the vascularisation and bone formation (Fig. 7b-e), and that the bone-like appearance of the tissue was not merely due to appositional mineralisation of the scaffolds. Additionally, the hard tissue layer showed the presence of OCN as evidenced by immunohistochemical staining, further suggesting that the mineralised cryogels promoted bone formation in vivo (Fig. 8). It is important to note that the presence of the mineral layer was expected to reduce the effective size of the pores. Mercury intrusion porosimetry revealed that mineralisation only reduced average pore diameter by approximately $2 \mu \mathrm{m}$, suggesting that mineralisation was unlikely to restrict access into construct interior through pore closure. 

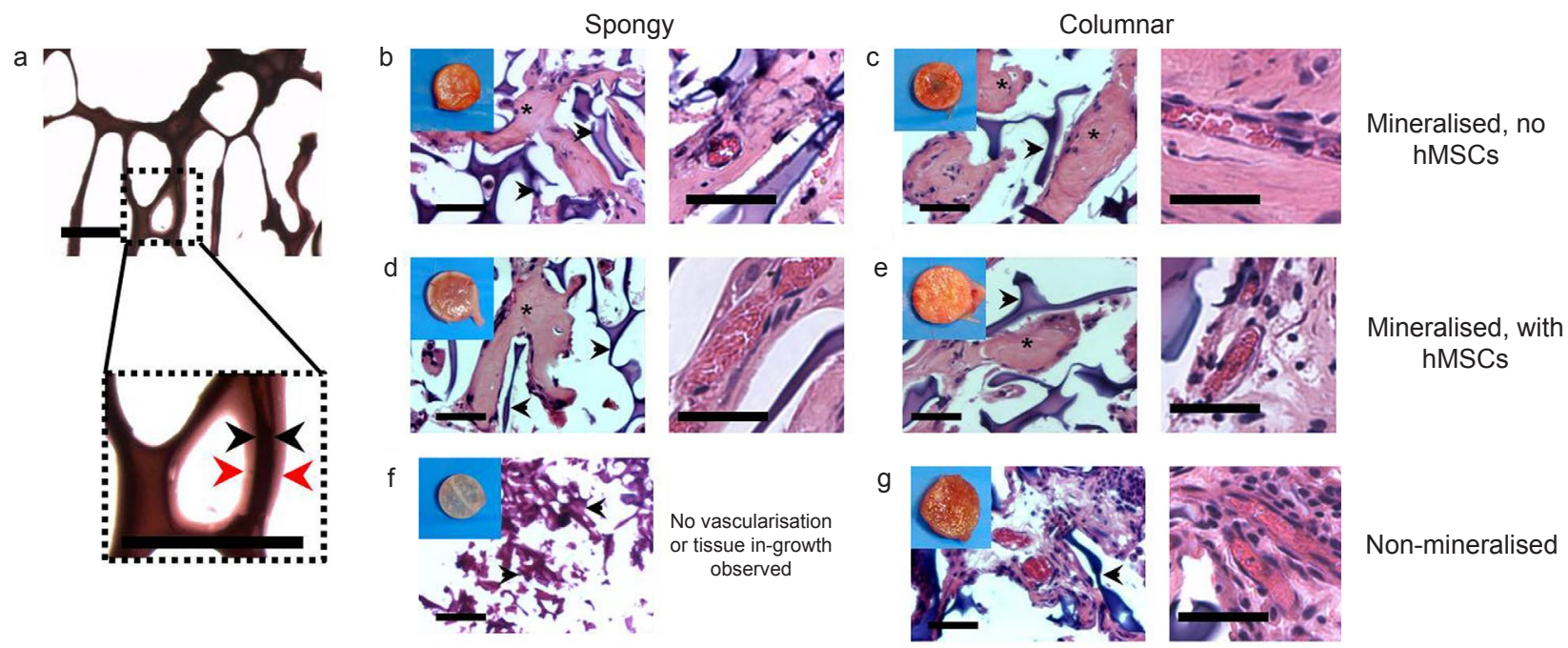

Fig. 7. (a) $\mathrm{H} \& \mathrm{E}$ staining of acellular mineralised cryogel after 7 days of appositional mineralisation in vitro under simulated physiological conditions. Black arrowheads indicate the cryogel scaffold, red arrowheads indicate the eosinophilic mineral layer. Scale bars indicate $100 \mu \mathrm{m}$. (b-g) Histological analysis and gross photographs of constructs (inset) after 9 weeks of subcutaneous implantation. (b) Mineralised, spongy cryogels without hMSCs, (c) mineralised, columnar cryogels without hMSCs, (d) mineralised, spongy cryogels with hMSCs, (e) mineralised, columnar cryogels with hMSCs, (f) non- mineralised, spongy cryogels (without hMSCs), (g) non-mineralised, columnar cryogels (without hMSCs). Images on the right indicate the presence of lumen-like structures within the respective scaffold as evidence of vascularisation. Black arrowheads indicate the scaffold area, * indicates bone tissue. Scale bars in $\mathbf{b}-\mathbf{g}$ represent $50 \mu \mathrm{m}$.
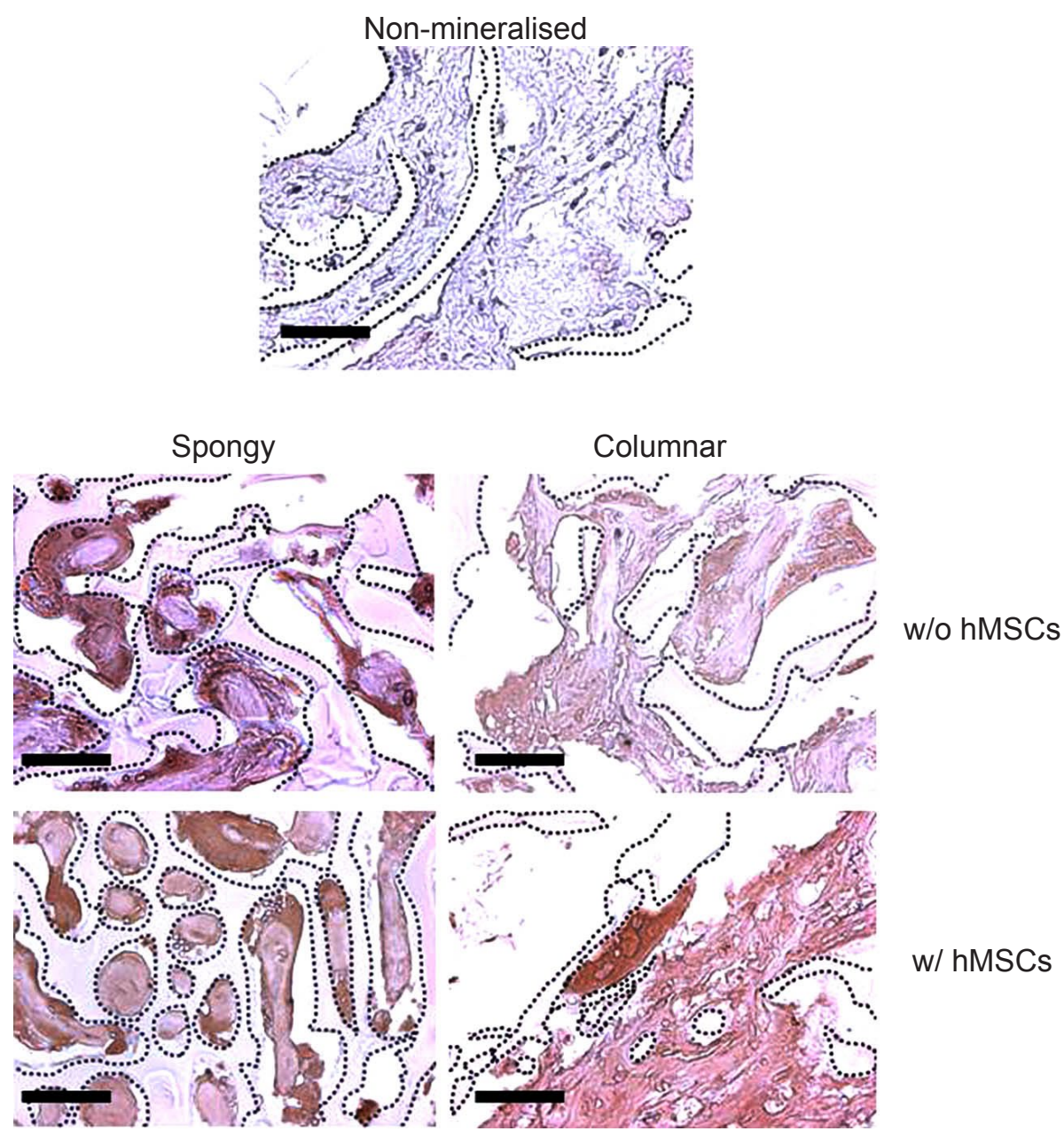

Fig. 8. Immunohistochemical staining for osteocalcin (brown) in cryogel constructs implanted subcutaneously in nude rats for 9 weeks. Dotted lines represent the scaffold area. Scale bars represent $50 \mu \mathrm{m}$. 
Non-mineralised cryogels (groups i-ii), on the other hand, showed a dramatically different response from their mineralised counterparts. Unlike the mineralised cryogels, no hard tissue formation was observed even at 9 weeks of implantation for non-mineralised cryogels, results supported by the lack of hard tissue detection in micro-CT (data not shown) and digital X-rays (Fig. 6a). Moreover, unlike in the mineralised cryogels, the pore architecture was seen to play a major role in host cell infiltration into the non-mineralised cryogels. Non-mineralised cryogels with spongy pore architecture (pore size of 50-60 $\mu \mathrm{m}$ ) showed negligible host cell infiltration, as evident from gross examination as well as histological analyses (Fig. 7f). Nonmineralised columnar cryogels (pore size of 100-150 $\mu \mathrm{m}$ ), on the other hand, showed host cell infiltration, but with abundant fibrous tissue and extensive vascularisation in the scaffold interior, without any bone information as indicated by the tissue morphology in H\&E staining and lack of OCN staining (Figs. 7g,8). The histology, lack of hard tissue formation and immunohistochemical analyses suggested that the non-mineralised columnar cryogels did not promote bone formation in vivo.

\section{Discussion}

During freezing of aqueous solutions, the morphology of the ice network is governed by the directionality of the cooling front and the solid-liquid interface between the solid ice and aqueous solution, both of which control the directionality of the ice network (Zhang et al., 2005). In this study, we manipulated the directionality of ice crystal formation by controlling the directionality of the cooling front and the solid-liquid interface (between the solid ice and the liquid polymer precursor solution) in order to create cryogel networks with different internal pore architectures. To create the directionality of internal pore structures, we have introduced a thin ice layer at the bottom of the mould to provide preferential nucleation sites, allowing for columnar ice dendrite growth without changing the precursor composition and content. The underlying ice layer provides a more drastic temperature gradient within the polymerising solution from top to the bottom in the columnar moulds than their spongy counterparts, which have the exact same precursor composition but a more uniform, isotropic temperature gradient because they lack the pre-formed ice layer. The presence of an ice layer in the bottom of the columnar mould prior to polymerisation leads to a cooling front that advances the growth of ice crystal perpendicular to the solid-liquid interfaces (unidirectionally upward from the bottom of the mould). This ice bed provides a template from which dendritic ice crystals grow in a lamellar fashion. This lamellar, oriented ice network provides directionally oriented lamellar, columnar pores upon thawing of the network. Spongy cryogels on the other hand, were prepared using isotropic cooling that led to randomly oriented, cellular pores as observed in our previous work that made use of isotropic cooling to form cryogels with randomly oriented, cellular pores (Hwang et al., 2010). Such manipulation of ice network formation by tuning the directionality of the cooling front has been previously used to alter the ceramic scaffold microarchitecture (Yunoki et al., 2006; Deville, 2008; Wegst et al., 2010). Indeed, a previous study reported the simultaneous presence of a columnar-like pore zone and spongy-like cellular pore zone during the freeze-casting of hydroxyapatite through manipulation of the freezing front morphology and the freezing kinetics (Deville et al., 2006). Our work, however, demonstrates for the first time, the application of this technique in the formation of synthetic polymeric scaffolds with distinctly different microarchitecture mimicking different structural attributes of bone tissues. Such a scaffold could be a tool to gain insight into the effect of pore microarchitecture on cellular functions in vitro and in vivo.

Our observation that despite having the same porosity, spongy cryogels promoted in vitro osteogenic differentiation of hMSCs shows the role of scaffold microarchitecture on cellular functions. This is consistent with a previous study, which shows a similar effect of pore architecture of freeze-casted hydroxyapatite scaffolds on murine osteoblast activity (Fu et al., 2009); in that study, isotropic, cellular interconnected pore structures (similar to the spongy pore architecture in our study) promoted ALP activity of the cells relative to lamellar, plate-like pores (similar to the columnar pore architecture in our study) despite a similar porosity between the two scaffold types. Despite the differences between the study by $\mathrm{Fu}$ et al. and our study vis-à-vis the material used as well as the cell types, their data concurs with our findings in that scaffolds with isotropic, cellular pore architecture are superior to those with oriented, lamellar pore structure in supporting early osteogenic differentiation of progenitor cells. Moreover, the study by Fu et al. utilised spongylike pore architecture with large pore size and columnar pore architecture with smaller pore size, while our study utilises spongy pore architecture with smaller pore size and columnar pore architecture with larger pore size. That the spongy pore morphology is superior in both studies despite this opposite trend in pore sizes suggests that the pore morphology plays a dominant role behind the enhanced osteogenesis in the spongy cryogels, while the difference in pore size is unlikely to be a significant contributor to the observed effect of microarchitecture on osteogenic differentiation in vitro.

The enhanced osteogenic differentiation of hMSCs in spongy cryogels could have been influenced by increased mass transport due to differences in interconnectivity between the pores. In fact, Uebersax et al. have previously demonstrated that pore interconnectivity can indeed influence osteogenic differentiation in vitro (Uebersax et al., 2006). In our study, the columnar scaffolds could have had fewer interconnections between the macropores owing to the plate-like lamellar pore structure; along with affecting nutrient transport throughout the scaffold, pore interconnectivity can also influence transport of cell-secreted factors throughout the scaffold, with more optimal transport expected in the case of the spongy scaffolds. Cell-cell communication via cell secreted soluble factors has been shown to play a significant role in the osteogenesis of MSCs (Birmingham et al., 2012). In addition to interconnectivity, tortuosity has also been 
proposed to affect osteogenesis (Kim et al., 2010); it is highly possible that the isotropic, dendritic pore structure of spongy scaffolds possessed a dramatically different tortuosity from the plate-like pores in the columnar scaffolds, which could have influenced the osteogenic differentiation of the hMSCs.

Another possible factor is the cell shape; hMSCs seeded in spongy cryogels appeared to assume spread morphology over the spongy cryogel pore surface, while hMSCs in columnar cryogels formed aggregates with roughly a spherical morphology in the pores without significant spreading. This could have been due to the fact that although the porosities were very similar between the two scaffold types, the pore surface area was higher (almost 2 -fold) in the spongy cryogels than the columnar cryogels, thereby allowing for increased available area for spreading of the cells in spongy cryogels following their seeding. As spread morphology has been previously demonstrated to favour osteogenesis of hMSCs, this could be another factor favouring osteogenic differentiation in the spongy cryogels (McBeath et al., 2004).

The formation of ectopic bone tissue in all mineralised cryogels, irrespective of pore architecture and the presence/absence of hMSCs suggest that the presence of the mineralised phase led to recruitment of endogenous progenitors from the surrounding host tissue. In addition to osteoinduction, the presence of a mineralised phase also promoted vascularisation of the implants, as evidenced by the gross appearance of the excised implants, which suggested vascularisation of mineralised acellular spongy scaffolds and the lack of vascularisation in acellular nonmineralised spongy scaffolds. This is in agreement with a previous study that showed improved angiogenesis in polymer-ceramic composites when compared to pure polymeric scaffolds (Gerhardt et al., 2011).

The mineralised matrix-mediated osteoinduction observed in this study is highly intriguing as ectopic bone formation in calcium phosphate-based scaffolds such as $\beta$-TCP and HA in the absence of any exogenously added cells has been conclusively established in large animal models such as dogs, pigs, sheep and primates, but most studies report that these materials are unable to induce bone formation in small animals such as rats and mice (Yang et al., 1996; Yuan et al., 2006). However, synthetic materialinduced bone formation in the absence of exogenous cells or biologics as observed in our study, while rare, is not unprecedented in rodent models (Selye et al., 1960; Pek et al., 2008; Seyedjafari et al., 2010; Barradas et al., 2012; Cheng et al., 2012). A previous study noted the formation of mature bone in glass diaphragms implanted subcutaneously in rats (Selye et al., 1960). Several of these studies employ composite matrices wherein calcium phosphates are either physically mixed with, or coated on an organic substrate and can induce ectopic bone formation (Pek et al., 2008; Seyedjafari et al., 2010) and bone defect healing (Kawai et al., 2009) in rodents. It is possible that the mineralised A6ACA-PEGDA matrices in our study provided a more effective mimic of bone tissue through their composite, biomineralised nature. In fact, work by Osathanon et al. has demonstrated that biomineralised fibrin matrices promoted enhanced osteoblastic activity compared to their non-mineralised counter parts physically embedded with minerals by physical mixing, providing further support of the influence of the biomineralisation process on the osteoinductivity of materials (Osathanon et al., 2008).

The ability of biomineralised matrices to promote ectopic bone tissue formation could be attributed to a variety of physicochemical cues arising from the mineralised matrix such as the topographical cues arising from the minerals, as well as chemical cues arising from the dynamic dissolution-reprecipitation of the mineralised phase (Chai et al., 2012). The dissolution-reprecipitation of mineralised materials leads to increased local $\mathrm{Ca}^{2+}$ and $\mathrm{PO}_{4}^{3-}$ concentrations, which have been demonstrated to promote osteogenic differentiation of progenitor cells in vitro (Chai et al., 2010; Chai et al., 2012; Phadke et al., 2012) and could play a role in osteoinduction by these materials in vivo (Le Nihouannen et al., 2005; Müller et al., 2008; Chai et al., 2010; Phadke et al., 2012). Ionic dissolution products from calcium-containing ceramics such as bioactive glasses have also been linked to a proangiogenic effect of these materials in vitro and in vivo (Gorustovich et al., 2010). Beyond regulating the local concentration of $\mathrm{Ca}^{2+}$ and $\mathrm{PO}_{4}^{3-}$ ions, the dissolutionreprecipitation of the mineral phase can also sequester pro-osteogenic and pro-angiogenic growth factors such as bone morphogenetic proteins (BMPs) and vascular endothelial growth factors (VEGFs), thereby potentially leading to the observed osteoinduction and vascularisation (Lee et al., 2011). Additionally, genetic factors relating to intra-species differences between different strains of the same species can influence bone formation. A recent study has demonstrated that in mice, the ability of calcium phosphates to induce ectopic bone formation was straindependent with specific strains showing far superior ectopic bone formation ability when compared to other strains (Barradas et al., 2012). It is possible that our results were influenced by specific genetic factors arising from the use of the athymic rnu/rnu strain of rats utilised in our study.

The differential host cell infiltration into the nonmineralised spongy and columnar cryogels could be attributed to the difference in pore size between the cryogels. A recent study demonstrated that a pore size of $100-150 \mu \mathrm{m}$ is more conducive to host cell infiltration into macroporous hydrogel scaffolds than a pore size of 25$50 \mu \mathrm{m}$ (Chiu et al., 2011); similarly in our study, the large pore size of the columnar PEGDA-co-A6ACA cryogels $(100-150 \mu \mathrm{m})$ could be more conducive to vascular ingrowth than the relatively smaller pore size $(50-60 \mu \mathrm{m})$ of the spongy cryogels, resulting in extensive host cell infiltration and vascularisation of the former but not the latter. However, the bioactivity imparted by the presence of the mineral layer was sufficient to overcome this issue, as evidenced by the vascularisation and host cell infiltration into the mineralised spongy cryogels, in stark contrast with the lack of host cell penetration observed in the nonmineralised spongy cryogels. 


\section{Conclusion}

We have demonstrated the ability to control pore architecture in macroporous cryogels during cryogelation by controlling the directionality of the cooling front, obtaining cryogels with a lamellar, columnar pore structure as well as spongy pore architecture. Further, we have demonstrated that in macroporous cryogel scaffolds, cellular, isotropic pore architecture promotes early osteogenic differentiation of hMSCs to a greater extent than lamellar, oriented pore structure. In vivo, the presence of a mineral phase in these cryogels promoted ectopic bone formation irrespective of pore architecture, although pore microarchitecture did significantly influence host cell infiltration and vascularisation in the absence of a mineral phase.

\section{Acknowledgements}

The authors gratefully acknowledge assistance from San Diego Pathologists Medical Group for assistance in sectioning of the in vivo implanted samples. A.P. gratefully acknowledges financial support from the NSF Socrates GK-12 fellowship (University of California, San Diego; NSF \#742551; PI: Maarten Chrispeels) and the Jacobs Fellowship (University of California, San Diego). The hMSCs used in this study were provided by the Institute for Regenerative Medicine (Texas A \& M University) through a grant from National Center for Research Resources of the National Institutes of Health (\#P40RR017447). This work was funded by the California Institute of Regenerative Medicine (RN2-00945).

\section{References}

Ayala R, Zhang C, Yang D, Hwang Y, Aung A, Shroff SS, Arce FT, Lal R, Arya G, Varghese S (2011) Engineering the cell-material interface for controlling stem cell adhesion, migration, and differentiation. Biomaterials 32: 3700-3711.

Barradas A, Yuan H, van der Stok J, Le Quang B, Fernandes H, Chaterjea A, Hogenes MCH, Shultz K, Donahue LR, van Blitterswijk C, de Boer J (2012) The influence of genetic factors on the osteoinductive potential of calcium phosphate ceramics in mice. Biomaterials 33: 5696-5705.

Benoit DSW, Schwartz MP, Durney AR, Anseth KS (2008) Small functional groups for controlled differentiation of hydrogel-encapsulated human mesenchymal stem cells. Nat Mater 7: 816-823.

Birmingham E, Niebur GL, McHugh PE, Shaw G, Barry FP, McNamara LM (2012) Osteogenic differentiation of mesenchymal stem cells is regulated by osteocyte and osteoblast cells in a simplified bone niche. Eur Cells Mater 23: 13-27.

Bruder SP, Jaiswal N, Ricalton NS, Mosca JD, Kraus KH, Kadiyala S (1998) Mesenchymal stem cells in osteobiology and applied bone regeneration. Clin Orth Relat Res 355: S247.
Chai YC, Roberts SJ, Schrooten J, Luyten FP (2010) Probing the osteoinductive effect of calcium phosphate by using an in vitro biomimetic model. Tissue Eng Part A 17: 1083-1097.

Chai YC, Carlier A, Bolander J, Roberts SJ, Geris L, Schrooten J, Van Oosterwyck H, Luyten FP (2012) Current views on calcium phosphate osteogenicity and the translation into effective bone regeneration strategies. Acta Biomater 8: 3876-3887.

Cheng L, Duan X, Xiang Z, Shi Y, Lu X, Ye F, $\mathrm{Bu} \mathrm{H}$ (2012) Ectopic bone formation cannot occur by hydroxyapatite/ $\beta$-tricalcium phosphate bioceramics in green fluorescent protein chimeric mice. Appl Surf Sci 262: 200-206.

Chiu Y-C, Cheng M-H, Engel H, Kao S-W, Larson JC, Gupta S, Brey EM (2011) The role of pore size on vascularization and tissue remodeling in PEG hydrogels. Biomaterials 32: 6045-6051.

Cowan CM, Shi YY, Aalami OO, Chou YF, Mari C, Thomas R, Quarto N, Contag CH, Wu B, Longaker MT (2004) Adipose-derived adult stromal cells heal criticalsize mouse calvarial defects. Nat Biotechnol 22: 560-567.

Curran JM, Chen R, Hunt JA (2006) The guidance of human mesenchymal stem cell differentiation in vitro by controlled modifications to the cell substrate. Biomaterials 27: 4783-4793.

Dalby MJ, Gadegaard N, Tare R, Andar A, Riehle MO, Herzyk P, Wilkinson CDW, Oreffo ROC (2007) The control of human mesenchymal cell differentiation using nanoscale symmetry and disorder. Nat Mater 6: 997-1003.

Deville S (2008) Freeze-casting of porous ceramics: A review of current achievements and issues. Adv Eng Mater 10: $155-169$.

Deville S, Saiz E, Tomsia AP (2006) Freeze casting of hydroxyapatite scaffolds for bone tissue engineering. Biomaterials 27: 5480-5489.

Engler AJ, Sen S, Sweeney HL, Discher DE (2006) Matrix elasticity directs stem cell lineage specification. Cell 126: 677-689.

Fu Q, Rahaman MN, Bal BS, Brown RF (2009) In vitro cellular response to hydroxyapatite scaffolds with oriented pore architectures. Mater Sci Eng C 29: 2147-2153.

Galante J, Rostoker W, Ray RD (1970) Physical properties of trabecular bone. Calcif Tissue Int 5: 236-246.

Gauthier O, Bouler J-M, Aguado E, Pilet P, Daculsi G (1998) Macroporous biphasic calcium phosphate ceramics: influence of macropore diameter and macroporosity percentage on bone ingrowth. Biomaterials 19: 133-139.

Gerhardt L-C, Widdows KL, Erol MM, Burch CW, Sanz-Herrera J, Ochoa I, Stämpfli R, Roqan IS, Gabe S, Ansari T, Boccaccini AR (2011) The pro-angiogenic properties of multi-functional bioactive glass composite scaffolds. Biomaterials 32: 4096-4108.

Gomes M, Holtorf H, Reis R, Mikos A (2006) Influence of the porosity of starch-based fiber mesh scaffolds on the proliferation and osteogenic differentiation of bone marrow stromal cells cultured in a flow perfusion bioreactor. Tissue Eng 12: 801-809.

Gorustovich A, Roether J, Boccaccini A (2010) Effect of bioactive glasses on angiogenesis: a review of in vitro and in vivo evidences. Tissue Eng Part B Rev 16: 199-207. 
Hutmacher DW, Schantz JT, Lam CXF, Tan KC, Lim TC (2007) State of the art and future directions of scaffoldbased bone engineering from a biomaterials perspective. J Tissue Eng Regen Med 1: 245-260.

Hwang NS, Varghese S, Puleo C, Zhang Z, Elisseeff J (2007) Morphogenetic signals from chondrocytes promote chondrogenic and osteogenic differentiation of mesenchymal stem cells. J Cell Physiol 212: 281-284.

Hwang NS, Zhang C, Hwang Y, Varghese S (2009a) Mesenchymal stem cell differentiation and roles in regenerative medicine. Wiley Interdisc Rev Syst Biol Med 1: 97-106.

Hwang Y, Zhang C, Varghese S (2009b) Poly (ethylene glycol) cryogels as potential cell scaffolds: effect of polymerization conditions on cryogel microstructure and properties. J Mater Chem 20: 345-351.

Hwang Y, Sangaj N, Varghese S (2010) Interconnected macroporous poly(ethylene glycol) cryogels as a cell scaffold for cartilage tissue engineering. Tissue Eng Part A 16: 3033- 3041.

Jaiswal N, Haynesworth SE, Caplan AI, Bruder SP (1997) Osteogenic differentiation of purified, cultureexpanded human mesenchymal stem cells in vitro. J Cell Biochem 64: 295-312.

Kadiyala S, Jaiswal N, Bruder SP (1997) Cultureexpanded, bone marrow-derived mesenchymal stem cells can regenerate a critical-sized segmental bone defect. Tissue Eng 3: 173-185.

Karageorgiou V, Kaplan D (2005) Porosity of 3D biomaterial scaffolds and osteogenesis. Biomaterials 26: 5474-5491.

Kasten P, Beyen I, Niemeyer P, Luginbühl R, Bohner M, Richter W (2008) Porosity and pore size of $\beta$-tricalcium phosphate scaffold can influence protein production and osteogenic differentiation of human mesenchymal stem cells: An in vitro and in vivo study. Acta Biomater 4: 1904 1915.

Kawai T, Anada T, Honda Y, Kamakura S, Matsui K, Matsui A, Sasaki K, Morimoto S, Echigo S, Suzuki O (2009) Synthetic octacalcium phosphate augments bone regeneration correlated with its content in collagen scaffold. Tissue Eng Part A 15: 23-32.

Kim K, Yeatts A, Dean D, Fisher J (2010) Stereolithographic bone scaffold design parameters: osteogenic differentiation and signal expression. Tissue Eng Part B Rev 16: 523-539.

Kühne JH, Bartl R, Frisch B, Hammer C, Jansson $\mathrm{V}$, Zimmer M (1994) Bone formation in coralline hydroxyapatite: effects of pore size studied in rabbits. Acta Orthopaedica 65: 246-252.

Lee JS, Suarez-Gonzalez D, Murphy WL (2011) Mineral coatings for temporally controlled delivery of multiple proteins. Adv Mater 23: 4279-4284.

Le Nihouannen D, Daculsi G, Saffarzadeh A, Gauthier O, Delplace Sv, Pilet P, Layrolle P (2005) Ectopic bone formation by microporous calcium phosphate ceramic particles in sheep muscles. Bone 36: 1086-1093.

Mastrogiacomo M, Scaglione S, Martinetti R, Dolcini L, Beltrame F, Cancedda R, Quarto R (2006) Role of scaffold internal structure on in vivo bone formation in macroporous calcium phosphate bioceramics. Biomaterials 27: 3230-3237.

McBeath R, Pirone DM, Nelson CM, Bhadriraju K, Chen CS (2004) Cell shape, cytoskeletal tension, and RhoA regulate stem cell lineage commitment. Dev Cell 6: 483-495.

Müller P, Bulnheim U, Diener A, Lüthen F, Teller M, Klinkenberg ED, Neumann HG, Nebe B, Liebold A, Steinhoff G (2008) Calcium phosphate surfaces promote osteogenic differentiation of mesenchymal stem cells. J Cell Mol Med 12: 281-291.

Osathanon T, Linnes ML, Rajachar RM, Ratner BD, Somerman MJ, Giachelli CM (2008) Microporous nanofibrous fibrin-based scaffolds for bone tissue engineering. Biomaterials 29: 4091-4099.

Oyane A, Kim HM, Furuya T, Kokubo T, Miyazaki T, Nakamura T (2003) Preparation and assessment of revised simulated body fluids. J Biomed Mater Res Part A 65: 188195.

Pek YS, Gao S, Arshad MSM, Leck KJ, Ying JY (2008) Porous collagen-apatite nanocomposite foams as bone regeneration scaffolds. Biomaterials 29: 4300-4305.

Phadke A, Chang CW, Varghese S (2010a) Functional Biomaterials for Controlling Stem Cell Differentiation. In: Biomaterials as Stem Cell Niche (Roy K, ed), Springer, Berlin Heidelberg, pp 19-44.

Phadke A, Zhang C, Hwang YS, Vecchio K, Varghese $\mathrm{S}$ (2010b) Templated mineralization of synthetic hydrogels for bone-like composite materials: role of matrix hydrophobicity. Biomacromolecules 12: 2060-2068.

Phadke A, Shih Y, Varghese S (2012) Mineralized synthetic matrices as an instructive microenvironment for osteogenic differentiation of human mesenchymal stem cells. Macromol Biosci 12: 1022-1032.

Schaffler MB, Burr DB (1988) Stiffness of compact bone: effects of porosity and density. J Biomech 21: 13-16.

Selye H, Lemire Y, Bajusz E (1960) Induction of bone, cartilage and hemopoietic tissue by subcutaneously implanted tissue diaphragms. Dev Genes Evol 151: 572585.

Seyedjafari E, Soleimani M, Ghaemi N, Shabani I (2010) Nanohydroxyapatite-coated electrospin poly(Llactide) nanofibers enhance osteogenic differneitation of stem cells and induce ectopic bone formation. Biomacromolecules 11: 3118-3125.

Tsuruga E, Takita H, Itoh H, Wakisaka Y, Kuboki Y (1997) Pore size of porous hydroxyapatite as the cellsubstratum controls BMP-induced osteogenesis. J Biochem 121: 317-324.

Uebersax L, Hagenmüller H, Hofmann S, Gruenblatt E, Müller R, Vunjak-Novokovic G, Kaplan D, Merkle HP, Meinel L (2006) Effect of scaffold design on bone morphology in vitro. Tissue Eng 12: 3417-3429.

Varghese S, Hwang NS, Ferran A, Hillel A, Theprungsirikul P, Canver AC, Zhang Z, Gearhart J, Elisseeff J (2010) Engineering musculoskeletal tissues with human embryonic germ cell derivatives. Stem Cells 28: 765-774.

Von Doernberg M-C, von Rechenberg B, Bohner M, Grünenfelder S, van Lenthe GH, Müller R, Gasser B, 
Mathys R, Baroud G, Auer J (2006) In vivo behavior of calcium phosphate scaffolds with four different pore sizes. Biomaterials 27: 5186-5198.

Wang X, Ni Q (2003) Determination of cortical bone porosity and pore size distribution using a low field pulsed NMR approach. J Orth Res 21: 312-319.

Wegst U, Schechter M, Donius A, Hunger P (2010) Biomaterials by freeze casting. Phil Trans R Soc A 368: 2099-2121.

Yang Z, Yuan H, Tong W, Zou P, Chen W, Zhang X (1996) Osteogenesis in extraskeletally implanted porous calcium phosphate ceramics: variability among different kinds of animals. Biomaterials 17: 2131-2137.

Yuan H, van Blitterswijk CA, de Groot K, de Bruijn JD (2006) Cross-species comparison of ectopic bone formation in biphasic calcium phosphate (BCP) and hydroxyapatite (HA) scaffolds. Tissue Eng 12: 1607-1615.

Yuan H, Fernandes H, Habibovic P, De Boer J, Barradas A, De Ruiter A, Walsh WR, Van Blitterswijk CA, De Bruijn JD (2010) Osteoinductive ceramics as a synthetic alternative to autologous bone grafting. Proc Natl Acad Sci USA 107: 13614-13619.

Yunoki S, Ikoma T, Monkawa A, Ohta K, Kikuchi M, Sotome S, Shinomiya K, Tanaka J (2006) Control of pore structure and mechanical property in hydroxyapatite/ collagen composite using unidirectional ice growth. Mater Letters 60: 999-1002.

Zeltinger J, Sherwood J, Graham D, Müeller R, Griffith L (2001) Effect of pore size and void fraction on cellular adhesion, proliferation and matrix deposition. Tissue Eng 7: $557-572$.

Zhang C, Aung A, Liao L, Varghese S (2009) A novel single precursor-based biodegradable hydrogel with enhanced mechanical properties. Soft Matter 5: 3831-3834.

Zhang H, Hussain I, Brust M, Butler MF, Rannard SP, Cooper AI (2005) Aligned two- and three-dimensional structures by directional freezing of polymers and nanoparticles. Nat Mater 4: 787-793.

\section{Discussion with Reviewers}

Reviewer I: H \& E staining shows pink staining that resembles bone staining, but could also simply represent eosin binding to a mineralised scaffold. Please comment. Authors: While we agree with the reviewer that the mineral component of the scaffolds could contribute to the eosinophilic staining, the tissue morphology (Fig. 7) and the other characteristics of the tissue sections indicate formation of bone tissue. Specifically, the presence of an eosinophilic matrix lined with cells on the exterior is a characteristic morphology of bone. Our scaffold (i.e., mineralised cryogels) in fact stained strongly for haematoxylin, and was purplish in colour, indicated by black arrowheads in Fig. 7 (in contrast to the pink coloured bone tissue, indicated by ' $*$ ' in Fig. 7b-e, left column images). Upon dehydration during the staining, the scaffold appears to have shrunk away from the neotissue. Moreover, the tissue shows that the cells (and not the eosinophilic matrix) is adjacent to the scaffold which has shrunk away from the tissue, providing further evidence that the tissue is in fact bone and not an artefact arising from appositional mineralisation of the scaffold. To delineate the effect of appositional mineralisation on the observed H\&E staining, we have prepared mineralised cryogels as stated in the manuscript and immersed them in simulated body fluid (m-SBF) (Oyane et al., 2003, text reference) for a period of 7 days at $37^{\circ} \mathrm{C}$ to simulate the non-osteogenic appositional mineralisation under physiological conditions. The H\&E staining (Fig. 7a) of these cryogels shows that while the mineral layer is slightly eosinophilic, the mineralised layer shrinks with the scaffold and has a very different appearance from that of the bone-like tissue observed in the ectopically implanted mineralised cryogels. Furthermore, we have confirmed the bone tissue formation in implanted mineralised cryogels by immunohistochemical staining for OCN (Fig. 8), which supports bone tissue formation in vivo.

Reviewer I: Osteoinduction by minerals, in the absence of transplanted biologic molecules or cells, has typically been observed only in dog, monkey, baboon, and some sheep/ goat studies. Observations of osteoinduction by mineral biomaterials in rodent models have been extremely rare. If osteoinduction is happening in vivo within the mineralised cryogels presented here, what is unique about these materials that allows them to promote osteoinduction?

Authors: The biomineralised scaffolds described in this study are developed through the templated mineralisation of polymeric networks, which allow for the nucleation of CaP minerals. These calcium phosphate minerals undergo dynamic dissolution/reprecipitation, responding to changes in the ion concentration of the extracellular milieu, to regulate the local concentration of $\mathrm{Ca}^{2+}$ and $\mathrm{PO}_{4}^{3-}$ ions (Chai et al., 2010; Phadke et al., 2012, text references). The dissolution/precipitation of $\mathrm{CaP}$ has also been shown to mediate adsorption and release of osteoinductive molecules such as BMP (Urist et al., 1984, additional reference; Lee et al., 2011, text reference). All of these factors could contribute to the observed biomineralised matrix-mediated osteoinduction. We also acknowledge the potential effects of genetic factors and the specific rodent strain used, as this has been recently shown to play a substantial role in the ectopic ossification induced by calcium phosphates in rodents (Barradas et al., 2012, text reference). There are also a few more studies that have demonstrated osteoinduction of calcium phosphates in rodents without exogenous biologics or cells, thus indicating that osteoinduction as observed by us in rodents is rare but not unprecedented (Pek et al., 2008; Seyedjafari et al., 2010, text references; Yang et al., 2011, additional reference).

Reviewer I: The approach described here, in which total porosity remains constant and the pore architecture is varied, may ultimately allow for specific pore variables to be isolated and studied. Are there specific design rules related to pore structure and osteogenesis that could stem from this general approach?

Authors: We believe findings from our study and in the literature seem to suggest that pore structure with spherical, isotropic pores is more conducive to in vitro osteogenesis than lamellar, column-shaped pores, irrespective of the 
pore size. Specific pore variables that could be isolated and studied include the pore size, pore interconnectivity and tortuosity of the pore network.

Reviewer II: The pore sizes generated by the authors are much smaller than what is currently suggested by the literature to be 'optimal' for bone, angiogenic and bone and angiogenic in-growth. Can the authors comment?

Authors: While previous reports do suggest a pore size of $>100 \mu \mathrm{m}$ as optimal for bone in-growth and angiogenesis, reports have also shown bone formation in scaffolds with $50 \mu \mathrm{m}$ pores (Zhao and Akao, 1997, additional reference); the bone formation and angiogenesis in our study are thus not unprecedented. Our study clearly shows that the mineralisation appeared to dramatically enhance vascularisation in addition to promoting bone formation; this pro-angiogenic and osteoinductive effect of the mineralised phase could have compensated for the smaller pore sizes in the spongy scaffolds allowing for their vascularisation and osteogenesis. Additionally, it is also important to note that the literature does show that while pore size affects bone in-growth, bone-formation and angiogenesis in vivo, the specific optimal pore sizes vary by animal model and specific scaffold material used (Karageorgiou and Kaplan, 2005, text reference).

Reviewer II: There appear to be two groups missing from the SubQ study (unmineralised spongy + cells; unmineralised columnar + cells). It is difficult to delineate the effect of scaffold versus cells without their inclusion? Can the authors comment?

Authors: The objective of the in vivo study was to determine whether the mineralised A6ACA scaffolds could induce ectopic bone formation, and if it is important to delineate the effect of scaffold versus the effect of the cells. Hence, we chose both acellular mineralised scaffolds and hMSC-seeded mineralised scaffolds for the in vivo study. The acellular scaffolds would provide insights regarding the osteoinductive capacity of the scaffolds alone and the role of mineralisation towards this, while the hMSC-seeded scaffold would provide insights into the role of exogenously added progenitor cells on ectopic bone formation. Additionally, our previous work demonstrates that in the absence of soluble osteogenic stimulation, nonmineralised A6ACA-PEGDA materials do not promote osteogenic differentiation of hMSCs in vitro (Phadke et al., 2012, text reference) and thus, we did not include hMSC-seeded cryogels in the in vivo study.

\section{Additional References}

Urist MR, Huo YK, Brownell AG, Hohl WM, Buyske J, Lietze A, Tempst P, Hunkapiller M, DeLange RJ (1984) Purification of bovine bone morphogenetic protein by hydroxyapatite chromatography. Proc Natl Acad Sci USA 81: 371-375.

Yang R, Ye F, Cheng L, Wang J, Lu X, Shi Y, Fan H, Zhang X, Bu H (2011) Osteoinduction by Ca-P biomaterials implanted into the muscles of mice. J Zhejiang Univ Sci B 12: 682-690.

Zhao P, Akao M (1997) Preparation and characterization of double layered coating composed of hydroxyapatite and perovskite by thermal decomposition. Biomed Mater Eng 7: $67-81$. 